\title{
Research on Temperature Factors of Phosphgypsumin Microwave Field with Computer Numerical Simulation
}

\author{
Shuai $\mathrm{Li}^{1, \mathrm{a}}$, Zhi-man Zhao ${ }^{1, \mathrm{~b}^{\star}}$, Si-Chen Quan ${ }^{1}$, Feng $\mathrm{Gao}^{1}$, Man Shi ${ }^{2, \mathrm{c}}$ \\ ${ }^{1}$ Faculty of Civil Engineering and Mechanics, Kunming University of Science and Technology, \\ Kunming,Yunnan,650500, P.R.China \\ ${ }^{2}$ national policy consulting center,Beijing,100000, P.R.China \\ ae-mail: 1130624808@qq.com, b, ${ }^{*}$ e-mail: Izd2005@126.com, ${ }^{\mathrm{c} e m a i l}:$ shiman88@126.com
}

Keywords: Microwave; Phosphogypsum; MATLAB; Dielectric Constant; Thermal Conductivity

\begin{abstract}
In this paper, phosphgypsumwas processed by the method of microwave heating, and the variation of the temperature curve of phosphgypsumwas studied by means of software MATLAB, and their causes was also analyzed. The results show that in the early stages of heating phosphgypsum, the relationship between temperature and time is linear, mainly related to the dielectric constant of phosphogypsum; in the later stages of heating phosphogypsum, the relationship between temperature and time is quadratic linear, mainly related to the thermal conductivity of the material.
\end{abstract}

\section{Introduction}

Phosphogypsum is a kind of waste residue, which contains calcium phosphate dehydrate as its main ingredient, discharged from the production of phosphoric acid. It contains non-decomposed phosphate and a small amount of organics, which are the most important industrial byproducts in the production of phosphorus chemical [1]. And with 1t phosphate produced, there will be about $5 \mathrm{t}$ phosphogypsum emissions. As a result, the great amount of phosphogypsum not only causes large areas land occupied but also pollutes the environment seriously. The average utilization rate of phosphogypsum is only $4.5 \%$ in the world. And the utilization rate of phosphogypsum is low in China, compared to Japan, South Korea, Germany and other developed countries, which is less than 20\% [2-3]. The method of heating phosphogypsum treatment comprises the microwave heating, the autoclave and the calcination heating. Relative to the other two methods, the microwave has advantages on safety and sanitation [4]. $\beta$ hemihydrate gypsum got by the method of heating phosphogypsum treatment can be used to produce cement retarder, gypsum board and gypsum block, so the utilization of phosphogypsum can be improved [5-6]. For the temperature overshoot phenomenon in the process of microwave heating and the complex composition of phosphogypsum, there are certain problems for determining the heating time. This paper aims to fit the temperature curve of phosphogypsum by MATLAB software, and get the equation expression of the temperature curve, and then solve the deterministic problem of temperature and heating time.

\section{Experimental parameters}

(1)Microwave oven: Model JOYN-M1; rated voltage: AC220V/50Hz; Rated Power: 1.5KW; Rated microwave power: $0.8 \mathrm{KW}$; Rated microwave frequency: $2450 \pm 50 \mathrm{MHz}$; the cavity size of microwave: $110 \mathrm{~mm} \times 110 \mathrm{~mm} \times 110 \mathrm{~mm}$.

(2)Phosphogypsum: The experimental sample of Yuntianhua Corporation appears pale gray; the chemical composition analysis as shown in Table 1.

Table 1 Phosphogypsum component

\begin{tabular}{cccccccc}
\hline component & $\mathrm{SiO}_{2}$ & $\mathrm{Al}_{2} \mathrm{O}_{3}$ & $\mathrm{TFe}_{2} \mathrm{O}_{3}$ & $\mathrm{MnO}$ & $\mathrm{MgO}$ & $\mathrm{CaO}$ & $\mathrm{K}_{2} \mathrm{O}$ \\
\hline Percentage\% & 14.52 & 1.66 & 0.15 & 0.005 & 0.17 & 31.94 & 0.22 \\
\hline component & $\mathrm{Na}_{2} \mathrm{O}$ & $\mathrm{TiO}_{2}$ & Loss & $\mathrm{P}_{2} \mathrm{O}_{5}$ & $\mathrm{SO}_{3}$ & $\mathrm{Cl}$ & $\mathrm{CO}_{2}$ \\
\hline Percentage\% & 0.1 & 0.058 & 4.02 & 0.94 & 45.38 & 0.027 & $<0.30$ \\
\hline
\end{tabular}


Notes: the content of $\mathrm{CaO}$ and $\mathrm{SO}_{3}$ is highest, and the content of $\mathrm{SiO}_{2}$ is relatively high, and the amount of metal compounds is small.

(3)temperature parameters: phosphogypsum weighed $102.5 \mathrm{~g}$, the heating time was $16 \mathrm{~min}$, the upper temperature limit was $200^{\circ} \mathrm{C}, 210^{\circ} \mathrm{C}$. The temperature data during the microwave heating is shown in Table 2. The temperature data after the microwave heating is shown in Table 3.

Table 2 The temperature data during the microwave heating

\begin{tabular}{cc|cc|cc}
\hline $\mathrm{TEMP} /{ }^{\circ} \mathrm{C}$ & Time $/ \mathrm{min}$ & $\mathrm{TEMP} /{ }^{\circ} \mathrm{C}$ & $\mathrm{Time} / \mathrm{min}$ & $\mathrm{TEMP} /{ }^{\circ} \mathrm{C}$ & $\mathrm{Time} / \mathrm{min}$ \\
\hline 28 & 0.000 & 75 & 3.883 & 125 & 13.733 \\
30 & 0.383 & 80 & 4.383 & 130 & 14.100 \\
35 & 0.917 & 85 & 5.500 & 135 & 14.450 \\
40 & 1.317 & 90 & 6.450 & 140 & 14.733 \\
45 & 1.667 & 95 & 7.250 & 145 & 15.083 \\
50 & 2.017 & 100 & 8.050 & 150 & 15.417 \\
55 & 2.333 & 105 & 9.733 & 155 & 15.717 \\
60 & 2.683 & 110 & 10.350 & 160 & 15.833 \\
65 & 3.050 & 115 & 11.867 & 165 & 16.066 \\
70 & 3.400 & 120 & 12.850 & & \\
\hline
\end{tabular}

Table 3 The temperature data after the microwave heating

\begin{tabular}{cc|cc|cc|cc}
\hline TEMP $/{ }^{\circ} \mathrm{C}$ & Time $/ \mathrm{min}$ & $\mathrm{TEMP} /{ }^{\circ} \mathrm{C}$ & $\mathrm{Time} / \mathrm{min}$ & $\mathrm{TEMP} /{ }^{\circ} \mathrm{C}$ & $\mathrm{Time} / \mathrm{min}$ & $\mathrm{TEMP} /{ }^{\circ} \mathrm{C}$ & $\mathrm{Time} / \mathrm{min}$ \\
\hline 165 & 0.000 & 217 & 12.884 & 165 & 50.567 & 110 & 104.767 \\
170 & 0.267 & 215 & 16.367 & 160 & 54.334 & 105 & 112.217 \\
175 & 0.567 & 210 & 21.367 & 155 & 58.184 & 100 & 120.050 \\
180 & 0.934 & 205 & 24.950 & 150 & 62.150 & 95 & 129.400 \\
185 & 1.350 & 200 & 28.167 & 145 & 66.434 & 90 & 138.684 \\
190 & 1.800 & 195 & 31.267 & 140 & 70.950 & 85 & 148.717 \\
195 & 2.350 & 190 & 34.467 & 135 & 75.767 & 80 & 159.684 \\
200 & 2.984 & 185 & 37.567 & 130 & 80.767 & 75 & 172.034 \\
205 & 3.867 & 180 & 40.517 & 125 & 86.050 & 70 & 185.017 \\
210 & 5.434 & 175 & 43.950 & 120 & 91.517 & 65 & 199.817 \\
215 & 8.000 & 170 & 47.167 & 115 & 97.784 & 60 & 214.817 \\
\hline
\end{tabular}

MATLAB data fitting

MATLAB is a kind of software with the powerful graphical modeling and simulation. In order to analyze the variation of the curve, this article used MATLAB to fit the curve of the temperature data.

Input data

Input the data of table 2, table 3 according to MATLAB program language.

Plot, then analysis the variation of the curve and explain its reasons.

> > plot $(x, y)$ \%plot the curve of the data, shown in Fig 1, Fig2.

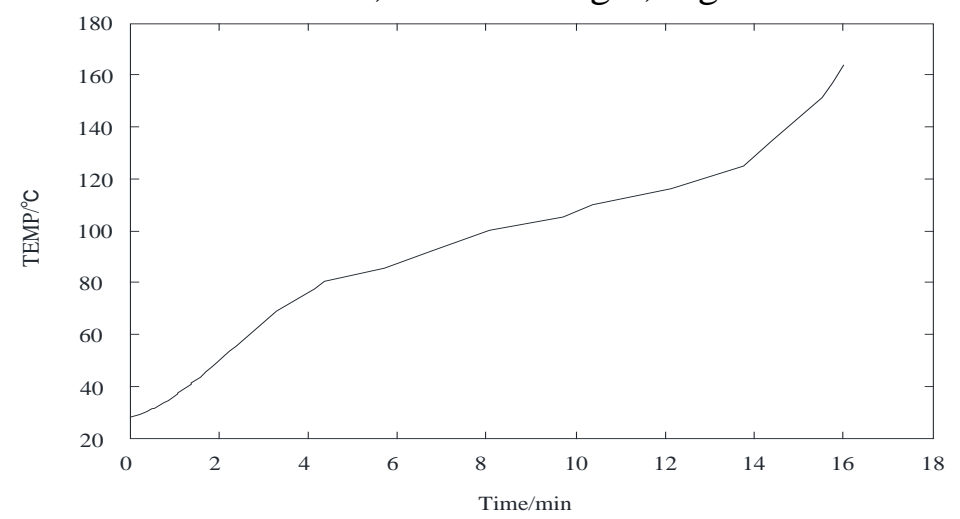

Fig.1 Relationship curve of time and temperature during the microwave heating 


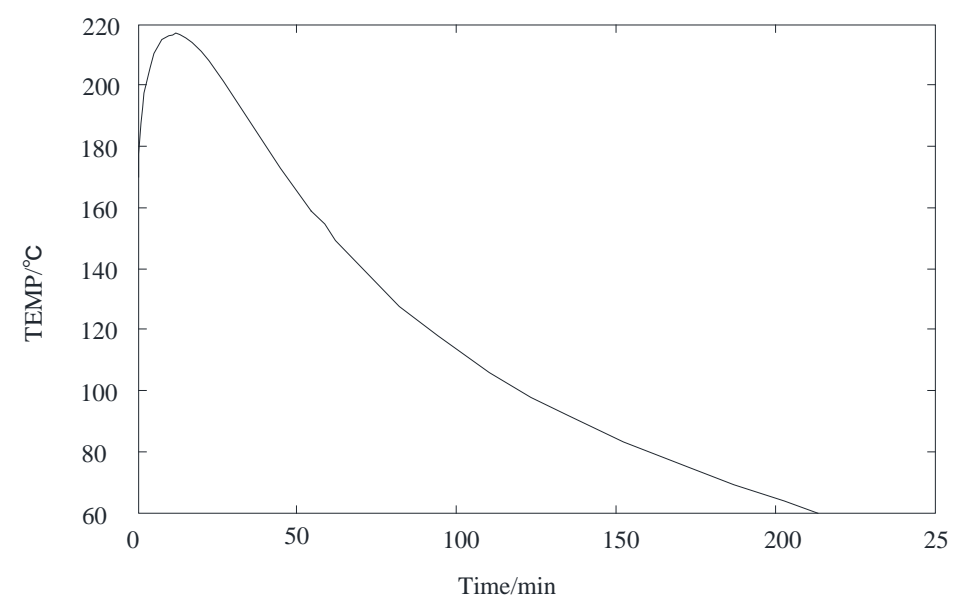

Fig.2 Relationship curve of time and temperature after the microwave heating

It could be obtained from Fig 1 that the characteristic of relationship between time and temperature appeared piecewise linear. It could be obtained from Fig 2 that the temperature continued to rise after the end of microwave heating, namely the temperature overshoot phenomenon; the temperature came to fall when it reached the maximum and the characteristic of relationship between time and temperature appeared linear quadratic.

By means of the microwave absorption, the temperature of phosphogypsum got rose. The microwave power that per unit volume of phosphogypsum absorbs in per unit time is:

$P=2 \pi f \varepsilon_{0} \varepsilon^{\prime \prime} E^{2}$

Wherein, $\mathrm{P}$ represents the power density of phosphogypsum microwave absorption $\left(\mathrm{W} / \mathrm{cm}^{3}\right)$; $\mathrm{f}$ represents the microwave frequency $(1 / \mathrm{s}) ; \varepsilon_{0}$ represents permittivity in vacuum $(8.854 \times 1014 \mathrm{~F} / \mathrm{cm})$; $\varepsilon^{\prime \prime}$ is the virtual part of the permittivity; E represents the intensity of the electric field $(\mathrm{V} / \mathrm{cm})$.

Heating rate of phosphogypsum is:

$$
\frac{d T}{d t}=\frac{2 \pi f \varepsilon_{0} \varepsilon^{\prime \prime} E^{2}}{\rho C_{p}}
$$

$\rho$ is the apparent density of phosphogypsum $\left(\mathrm{g} / \mathrm{cm}^{3}\right) ; C_{p}$ isthe specific heat of phosphogypsum ( J/g.K)

It could be obtained from the formula (2) that the relation between the rate of heating and permittivity was primarily linear after the test substance was defined. In the initial of microwave heating, solid and liquid in phosphogypsum were simultaneously heated. For the reason that the permittivity of phosphogypsum was large than that of liquid water, the rate of heating was rapid. In the interim of microwave, the evaporation of liquid inside the phosphogypsum was in progress mainly. And in this stage, due to the impact of the lower permittivity of water vapor, the rate of heating in phosphogypsum overall was slower. In the latter part of microwave heating, with all water inside phosphogypsum evaporated, the rate of heating increased over the initial one when the test substance got rid of the adverse impact of the lower permittivity of water. The phenomenon of piecewise linear presented in MATLAB fitting curve during microwave heating is explained, which is shown in Fig 1.

When the microwave generator stopped working, the internal temperature got lower by way of the thermal transmission between phosphogypsum and the thermocouple. It took a certain period of time when calories pass through a certain path, so the displayment of temperature would lag, and that is the reason for the temperature overshoot phenomenon.

At the stage of temperature decline, the internal temperature of microwave oven was to fall by the thermal transmission between the microwave oven and the environment outside of the microwave oven. The mode of thermal conduction was assumed to be flat wall thermal conduction. The heat 
conduction of flat wall was proportional to the temperature difference between both sides of the flat wall surface. The equation of heat flux that gets through the flat wall is:

$$
\phi=\frac{\lambda}{\delta} \Delta t S
$$

Wherein, $\varphi$ represents the total heat flux through the flat wall (W) ; S represents the wall area $\left(\mathrm{m}^{2}\right) ; \delta$ represents the wall thickness $(\mathrm{m}) ; \Delta \mathrm{t}$ represents the temperature difference between both sides of the wall surface $\left({ }^{\circ} \mathrm{C}\right)$.

In the case that the experimental apparatus had been determined, the wall area and the wall thickness were constant, so it means that both of the variables do not change with time. The conclusion is that the heat flux is only relevant to the temperature difference between both sides of the wall surface.

With the oven temperature getting lower, the temperature difference would gradually reduce, and as a result that the heat flux would gradually decrease. As shown in Fig 2, the absolute value of the temperature curve slope showed the trend as gradually decreasing. In the temperature rise stage, the heating rate was mainly associated with the dielectric constant of phosphogypsum; in the temperature drop stage, the heating rate was mainly associated with the thermal transmission between the experimental equipment and the external environment. And that is the reason for the characteristics of the fitting curve.

According to the piecewise linear characteristics that the fitting curve presents during the microwave heating, this article adopted the method of piecewise fitting.

The result fitted by MATLAB software is:

$$
\mathrm{F}\left(\mathrm{x}_{1}\right)=\left\{\begin{array}{c}
12.7507 \mathrm{x}+25.0883,0 \leq \mathrm{x}_{1}<4.383 ; \\
4.7277 \mathrm{x}+59.8719,4.383 \leq \mathrm{x}_{1}<13.733 \\
16.7057 \mathrm{x}-105.8307,13.733 \leq \mathrm{x}_{1} \leq 16.066
\end{array}\right.
$$

After the microwave heating, the temperature overshoot phenomenon has a different principle to the reason for the temperature drops in the stage, so this article adopted the method of segmentationg to progress the fitting curve.

The result fitted by MATLAB software is:

$$
\mathrm{F}\left(\mathrm{x}_{2}\right)\left\{\begin{array}{c}
0.00655 \mathrm{x}_{2}{ }^{3}-1.7864 \mathrm{x}_{2}{ }^{2}+16.1136 \mathrm{x}_{2}+165.9773,0 \leq \mathrm{x}_{2}<12.884 ; \\
0.0039 \mathrm{x}_{2}{ }^{2}-1.6497 \mathrm{x}_{2}+240.2297,12.884 \leq \mathrm{x}_{2} \leq 214.2297
\end{array}\right.
$$

The effectiveness of the obtained equation was analyzed by the method of regression in MATLAB. The stats for the first value showed that the regression equation of confidence is 1 , the third value is zero, refused to "H0: $b=0$ ", namely the regression model was established.

The comparison between the experimental data and the fitting curve is shown in Fig 3, Fig 4.

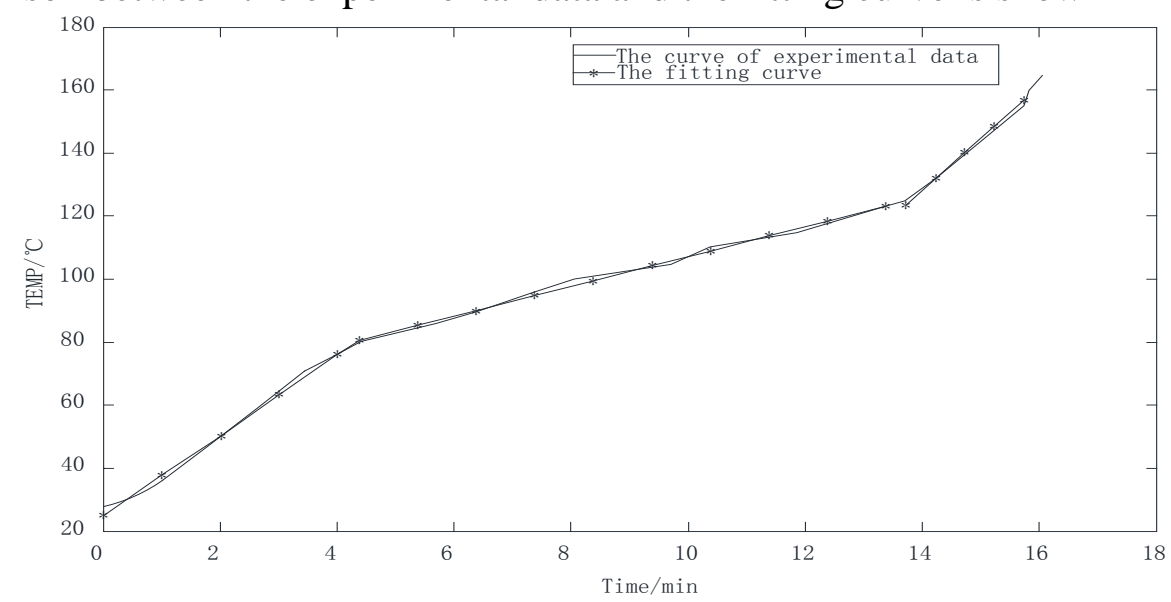

Fig.3 The experimental curve and the fittng curve $\mathrm{F}\left(\mathrm{x}_{1}\right)$ 


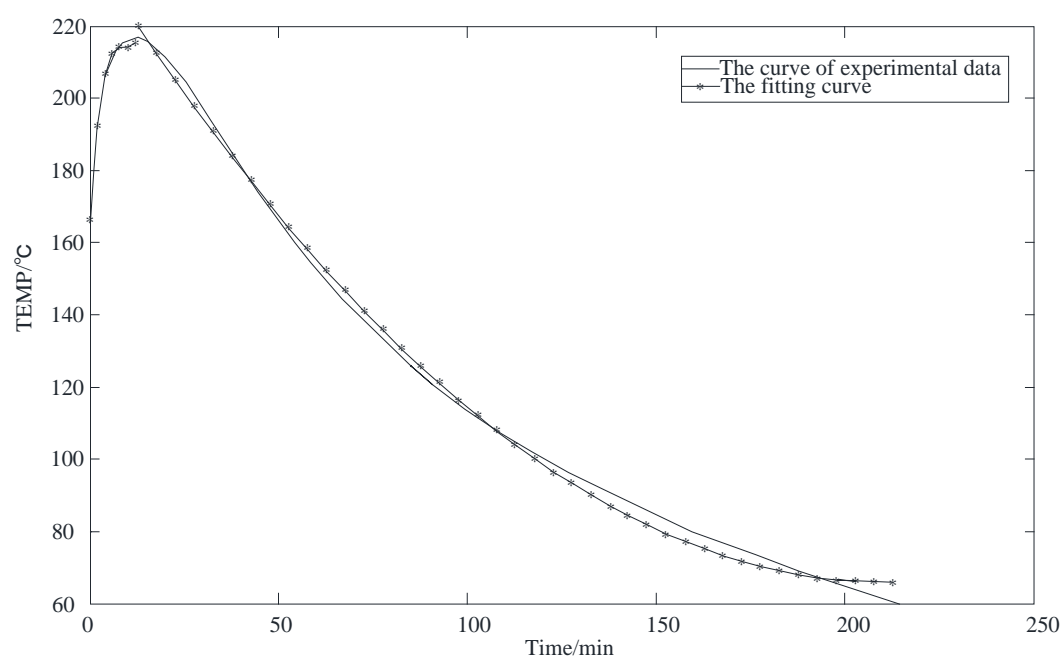

Fig.4 The experimental curve and the fitting curve $\mathrm{F}\left(\mathrm{x}_{2}\right)$

It could be seen from Fig 3 and Fig 4 that the fitting function fitted well with the experimental data.The heating time of phosphogypsum and the total time needed for a trial can be determined by function (4)(5). Assumed that the heat target temperature of phosphogypsum is already known, for example, $\mathrm{F}\left(\mathrm{x}_{1}\right)$ function can be used to calculate the microwave heating time, while $\mathrm{F}\left(\mathrm{x}_{2}\right)$ function can be used to calculate the overshoot temperature. If the overshoot temperature exceeds the maximum limit temperature, the microwave heating time should be reduced until the maximum temperature reaches $300^{\circ} \mathrm{C}$. And in order to measure the total time needed for the experiment, the time required during the temperature of the phosphogypsum sample reduced to room temperature should be considered. The fitting curve equation of phosphogypsum temperature drops shows quadratic linear characteristics. And its derivative, which is only related to the temperature difference between microwave cavity and indoor, gradually decreases with time. That means the equation form do not change with the increase of temperature limit. The total time required for the experiment can be derived by the method of back calculation when the upper temperature limit is substituted into $\mathrm{F}\left(\mathrm{x}_{2}\right)$ function. In addition, the maximumtemperature can be determined by the known heating time, and then with the substitution of the maximum temperature into $\mathrm{F}\left(\mathrm{x}_{2}\right)$ function the total time required can be also obtained.

\section{Conclusion}

Overshoot on temperature is a common phenomenon by the method of microwave heating phosphogypsum. In this paper, it not only saves the time needed for a large number of experiments and reduces the experiment funds by using MATLAB software to fit the function of the experimental data. Furthermore, it avoids the negative influence of repeated experiments. On the basis of previous studies, this article studies the factors which influence the temperature change of phosphogypsum in the microwave field. It is identified that the heating temperature variation is mainly associated with the dielectric constant of phosphogypsum during microwave heating; the heating temperature variation is mainly associated with the temperature difference between microwave cavity and indoor after microwave heating. The rationality of the fitting function is determined by regression analysis and the comparison between the experimental data curve and fitting function curve. The fitting function of phosphogypsum temperature curve can provide certain theory basis to determine the heating time and the limit of temperature. Finally, the application of the fitting function obtained in this article is briefly described.

\section{Acknowledgement}

In this paper, the research was sponsored by the National Natural Science Foundation (Project No. 51264017). 


\section{References}

[1] Yang Peihao:Comprehensive Utilization of Phosphogypsum,China Resources Comprehensive Utilization,1(27),(2009),p13-15.

[2] JIA Xingwen, Wu Zhou, Ma Ying:Present Status of Phosphogypsum Utilization in Building Materials, Materials Review,23(12),(2013),p139-146.

[3] Ye Xuedong: Present status, problems and suggestions of phosphogypsum utilization in China,Phosphate \& Compound Fertilizer,1(26),(2009),p5-7.

[4] Zhen qizhu, Jian zhou:Rapid growth of $\mathrm{ZnO}$ hexagonal tubes by direct microwave heating,International Journal of Minerals, Metallurgy and Materials,1(17),p80-85.

[5] Yang Yuehua, Shu Yizhou:Some suggestions about phosphogypsum utilization in Ymman province,Inorganic Chemicals Industry,12(44),(2012),p4-8.

[6] Du lushan, Ming dazeng, Lizhixiang, Liyonghui:Utilization and Recovery of Phosphogypsmn,Technology\&Development of Chemical Industry,4(39),(2010),p25-28.

[7] N.Standish,H. Worner, G. GuPta J.: Microwave Power and Electeromagnetic Energy [J],1990(2):75.

[8] L. Solymav, D. Walsh: Lectures on the Electric Properties of materials IJ],London,Oxford University Press,1976

[9] Chen liangbo, Zhangyaqing:Study on Curve Fitting Based on Least Square Method,Journal of WUXI Institute of Technology,5(11),(2012),p52-55.

[10] Liu qiao, Liu lixin, Jin zihao, Zhao mingju, Qi xiaohui:The Determination of Residence Time Distribution for a Reactor Based on Curve Fitting Toolbox,Computers and Applied Chemistry,4(30),(2013),p365-369.

[11] Guo yueshao:Curve Fitting Based on MATLAB and the Application on the Hall Effect Experiment,Laboratory Science,4(16),(2013),p24-26. 